\title{
AULA DE CAMPO COMO ESTRATÉGIA COMPLEMENTAR NO ENSINO DE CRIPTÓGAMAS E ESPERMATÓFITAS
}

\author{
Field class as a complementary strategy in the teaching of cryptogams and \\ spermatophytes
}

Aparecida Barbosa de Paiva - UECE / CE, Brasil. Fabrício Bonfim Sudério-UECE/CE, Brasil.

RESUMO: O presente artigo tem o objetivo de relatar uma experiência na monitoria das disciplinas de Morfologia e Taxonomia de Espermatófitas e Criptógamas, no Curso de Ciências Biológicas da FAEC/UECE, especificando e socializando as metodologias empregadas durante uma aula de campo em Pacoti-Ce. Os objetivos específicos e as atividades planejadas para a aula foram: realizar trilhas ecológicas e coletar espécies vegetais; dar instruções do manejo na coleta; orientar sobre conservação e relações ecológicas; fazer registros fotográficos; produzir exsicatas; aperfeiçoar o conhecimento da monitora; destacar as potencialidades da aula numa perspectiva progressista e interdisciplinar; e usar o aplicativo "Pl@nt Net" na identificação de espécies. Na turma de Espermatófitas as atividades foram planejadas com ênfase nas gimnospermas e nas angiospermas. Na turma de Criptógamas as atividades tiveram foco no estudo de briófitas, pteridófitas, fungos e líquens. Durante a aula, houve familiarização com a nomenclatura botânica vista nas aulas expositivas, produção de exsicatas, posterior utilização de chaves de identificação, e uso do aplicativo, que possibilitou a identificação das espécies coletadas e o registro de uma espécie que não constava na base de dados dessa ferramenta. Concluímos que a experiência proporcionou ganho intelectual, didático e científico a todos os envolvidos, além da percepção do potencial didático de uma aula de campo como estratégia complementar no ensino de botânica.

Palavras-chave: Aula de campo. Ensino de Botânica. Estratégia metodológica.

ABSTRACT: The present work had the objective to report an experience in the monitoring of the disciplines of Morphology and Taxonomy of Spermatophytes and Cryptogams in the Course of Biological Sciences of FAEC/UECE, specifying and socializing the methodologies used during a field course in Pacoti-Ce. The specific objectives and activities planned for the class were: to carry out ecological trails and to collect vegetal species; give management instructions on collection; guide conservation and ecological relations; make photographic records; produce exsiccates; improve the knowledge of the monitor; highlight the potential of the class in a progressive and interdisciplinary perspective; and use the "Pl@nt Net" application in species identification. In the Spermatophyte class, activities were planned with an emphasis on gymnosperms and angiosperms. In the Cryptogam class, the activities focused on the study of bryophytes, pteridophytes, fungus and lichens. During the lesson, there was familiarization with the botanical nomenclature seen in the lectures, production of exsiccates, later use of identification keys, and use of the application, which made it possible to identify the species collected and to record a species that was not on the basis of tool's data. We conclude that the experience provided intellectual, didactic and 
scientific gain to all involved, as well as the perception of the didactic potential of a field class as a complementary strategy in botany teaching.

\section{INTRODUÇÃO}

O ensino de Botânica, assim como o de outros conteúdos biológicos explorados na educação básica e no ensino superior, tem sido marcado por diversos entraves, tornando-se alvo de várias pesquisas acadêmicas acerca das motivações que levam à falta de interesse dos estudantes por esse conteúdo (ARRAIS; SOUSA; MASRUA, 2014).

Segundo Matos et al. (2016), um dos principais contribuintes para a falta de interesse pela botânica seria a forma de abordagem em sala de aula, restrita, em muitos casos, às aulas expositivas, o que intensifica cada vez mais a necessidade de reorganização dos procedimentos metodológicos empregados, no sentido de se estabelecer um vínculo direto com a realidade dos discentes, tornando o aprendizado mais eficiente.

Pelos motivos expostos, a busca por estratégias metodológicas que propiciem uma relação fluente entre a teoria apresentada em sala de aula e a realidade social, cultural e ambiental do aluno tem se intensificado muito nos últimos anos. Para Silva et al. (2014), além do caráter inovador de algumas estratégias de ensino, a diversificação na prática pedagógica dos docentes contribui significativamente para o seu crescimento profissional.

Existem diversas estratégias metodológicas que vêm sendo empregadas no intuito de oferecer uma aprendizagem mais significativa, dentre elas destacam-se: jogos didáticos, aulas práticas, vídeos, utilização das TIC e aulas de campo. Na opinião de Dias et al. (2017), essa última estratégia tem sido capaz de transpor os conhecimentos teóricos da aula para a realidade, além de proporcionar a ruptura do conhecimento limitado apenas às paredes da sala de aula.

Viveiro e Diniz (2009, p. 07) ressaltam as potencialidades da aula de campo nos cursos de Biologia, ao afirmarem que "as atividades de campo permitem a exploração de conteúdos conceituais, procedimentais e atitudinais". Por ser uma atividade que permite o contato direto com o ambiente, a aula de campo viabiliza o envolvimento do estudante e aguça seu potencial crítico pelo confronto criado entre teoria e prática, que muitas vezes 
Aula de campo como estratégia complementar no ensino de criptógamas e espermatófitas

é abstrato, fazendo com que os discentes participem ativamente da construção do conhecimento e não como meros receptores (VIVEIRO; DINIZ, 2009).

É importante destacar que as atividades de campo devem ser planejadas para além do aprendizado de um conteúdo, sobretudo nos cursos de licenciatura, de modo a propiciar que o discente visione o potencial pedagógico desta atividade e das metodologias empregadas em possíveis execuções futuras em campos de estágio, programas de formação de professores e no próprio campo de atuação dos licenciados, além de possibilitar o estreitamento da troca de saberes entre professores, colegas e demais envolvidos (KRASILCHIK, 2008).

Apesar de todas as vantagens pedagógicas de uma aula de campo, a inserção desta atividade ainda ocorre de forma eventual e esporádica, e isso decorre de alguns fatores, tais como: falta de preparo do docente para a condução de uma atividade prática em ambientes não explorados por ele; entraves burocráticos e financeiros da instituição; carência de tempo para o desenvolvimento da aula; e o preconceito de algumas instituições e demais docentes sobre a seriedade de atividades dessa natureza, que por vezes são interpretadas como "viagens e/ou passeios" (AGUIAR et al., 2017).

Pelos motivos expostos, é importante destacar que as aulas de campo não se fazem propriamente na chegada ao local de estudo, mas nas fases de planejamento, onde são observadas as potencialidades do local, a viabilidade financeira para tal atividade, o tempo despendido, a elaboração e a discussão do roteiro, de modo a enriquecer o conhecimento dos conteúdos abordados na disciplina em questão (GONÇALVES; DIAS; TERRA, 2010).

Para Nunes et al. (2015), a busca por alternativas metodológicas com viés prático advém do caráter inovador do professor da disciplina em sua prática docente, que além de estabelecer um modelo de ensino, pode alertar os estudantes, os monitores e os demais envolvidos com as disciplinas da área de botânica sobre a importância e a contribuição da inovação da prática docente no processo de aprendizagem.

A necessidade da monitoria nas disciplinas de "Morfologia e Taxonomia de Espermatófitas" e "Morfologia e Taxonomia de Criptógamas" no Curso de Ciências biológicas da FAEC/UECE (Faculdade de Educação de Crateús/Universidade Estadual do Ceará) surgiu de dois fatores fundamentais: dos estudos acadêmicos sobre as dificuldades que envolvem o ensino da botânica e da experiência do professor orientador 
com a necessidade de se buscar metodologias complementares com foco na contextualização do ensino e na aprendizagem interativa, com atributos atrativos para os estudantes.

Para Arnhold e Squalli (2014), a monitoria acadêmica funciona como um serviço de apoio pedagógico ao docente da disciplina, ao mesmo tempo em que oportuniza ao graduando o desenvolvimento de habilidades técnicas e de aprofundamento teórico dos conteúdos específicos abordados na disciplina.

Do exposto, o objetivo geral deste trabalho foi relatar a experiência vivenciada na monitoria acadêmica das disciplinas de "Morfologia e Taxonomia de Espermatófitas" e "Morfologia e Taxonomia de Criptógamas", ambas ministradas no Curso de Ciências biológicas da FAEC/UECE, especificando e socializando as metodologias empregadas durante a realização de uma aula de campo no Município de Pacoti-Ce, com o suporte do Campus Experimental de Educação Ambiental e Ecologia da Universidade Estadual do Ceará (UECE). Os objetivos específicos, as atividades planejadas e os enfoques da aula de campo foram: Realizar trilhas ecológicas com visualização e coleta de espécies vegetais; dar instruções sobre o manejo nas etapas de coleta; fornecer orientações sobre conservação e relações ecológicas; fazer registros fotográficos no campo; produzir exsicatas; aperfeiçoar o conhecimento da monitora sobre os conteúdos das disciplinas; destacar as potencialidades da aula de campo em uma perspectiva progressista e interdisciplinar; e fazer uso do aplicativo “Pl@nt Net” como ferramenta tecnológica complementar na identificação de espécies.

\section{MATERIAL E MÉTODO}

\subsection{PLANEJAMENTO DA AULA DE CAMPO}

A metodologia adotada para avaliar esta atividade é de caráter qualitativo com observação participante. Esse tipo de análise tem como fonte de dados o ambiente natural de onde os dados são coletados. Incluem-se também registros fotográficos, anotações de campo e demais materiais que possam auxiliar na interpretação da efetividade dessa estratégia metodológica (BOGDAN; BIKLEN, 1994). 
Aula de campo como estratégia complementar no ensino de criptógamas e espermatófitas

A aula de campo que foi realizada no município de Pacoti-Ce no período de 23 a 24 de maio de 2017 foi pensada durante uma das reuniões do colegiado do Curso de Ciências biológicas da FAEC/UECE e teve um viés interdisciplinar, já que professores de outras áreas, além da botânica, também fizeram parte. Isso ocorreu porque muitas disciplinas, dentre elas a de "Morfologia e Taxonomia de Espermatófitas" e a de "Morfologia e Taxonomia de Criptógamas", requerem estratégias complementares práticas de ensino.

Um dos fatores que levaram à escolha do local para a aula de campo (Pacoti-Ce) foi o fato de nas proximidades da cidade de Crateús-Ce não se observar locais com a infraestrutura e com as potencialidades naturais específicas destacadas pelos professores participantes das diferentes áreas no semestre 2016/2. No município de Pacoti-Ce, a UECE conta com o apoio do Campus Experimental de Educação Ambiental e Ecologia, que é destinado a pesquisas e estudos acadêmicos voltados à preservação ambiental e à biodiversidade da fauna e da flora local.

Outro motivo que levou à realização desta atividade foi a preocupação do professor da disciplina em dinamizar alguns conteúdos teóricos, de modo a promover um aprendizado mais efetivo, contextualizado e interdisciplinar para a turma.

As disciplinas de "Espermatófitas" e "Criptógamas" já vinham sendo complementadas com o uso de aulas práticas, contudo, o docente tinha ciência da necessidade de uma estratégia complementar mais efetiva com foco na complementação contextualizada destas disciplinas. Deste modo, foi decidido que a realização de uma aula de campo dessa natureza seria a atividade ideal para o preenchimento desta lacuna.

Também com o intuito de complementação didática de suas aulas, além da intenção de explorar os conhecimentos de forma interdisciplinar, quatro professores de diferentes áreas do Curso participaram da atividade, de modo que as áreas envolvidas foram: Botânica, Ecologia, Zoologia e Microbiologia. A logística desta atividade foi planejada em conjunto pelos docentes, ao mesmo tempo em que cada um fez um planejamento específico para as suas respectivas disciplinas e turmas, sempre com o apoio dos seus monitores e sempre com o intuito de dinamizar suas aulas e promover a interdisciplinaridade por meio da união destes diferentes saberes durante a aula de campo.

\subsection{PROCEDIMENTOS METODOLÓGICOS EMPREGADOS}


Após a escolha do local, o professor delineou algumas estratégias para trabalhar os procedimentos a serem realizados durante a atividade em campo. Uma dessas estratégias foi a realização de seminários com temáticas diretamente relacionadas às atividades e abordagens pretendidas para a aula no campo. Por meio dessa estratégia, muitas ideias foram trazidas pelos estudantes, como: a utilização de diferentes substâncias para a conservação de material botânico, as diferentes formas de conservação de órgãos vegetais, a utilização de prensas de madeira na preparação de exsicatas - constituindo-se como uma maneira de conservar essas espécies para a observação de turmas subsequentes -, e o uso do aplicativo "Pl@nt Net” para a identificação de espécies vegetais por meio de fotos.

O professor fez ainda um delineamento sobre o comportamento adequado de visitantes em reservas ecológicas, destacando a importância de se preservar as riquezas e as características do ambiente natural.

Ainda na fase de planejamento foram confeccionadas duas prensas de madeira pela monitora da disciplina, com a utilização de madeira usada e doada por uma madeireira da cidade de Crateús-Ce. Os demais materiais, como papelão, foram arrecadados pelos próprios estudantes da disciplina. Outros, como tesoura de poda, foram emprestados por outro docente da instituição, e os demais, como álcool, borrifadores e papel madeira foram adquiridos pelo professor da disciplina.

Com relação aos custos do deslocamento para a aula de campo, os estudantes da disciplina mobilizaram-se com a realização de rifas, com produtos que foram doados por comerciantes e por alguns docentes da FAEC/UECE, o que demonstra o potencial colaborativo que este tipo de atividade pode instigar.

Desta forma, o professor e a monitora delinearam algumas atividades a serem desenvolvidas durante a aula de campo, dentre elas a observação, o registro fotográfico e/ou a preparação de exsicatas por meio da coleta de espécies vegetais presentes em Pacoti-Ce que se aproximassem dos objetos de estudo das disciplinas de "Espermatófitas" e "Criptógamas", além da utilização do aplicativo "P1@nt Net” para a identificação das espécies de angiospermas. Os registros fotográficos das espécies abordadas na disciplina de "Criptógamas" foram selecionados e anexados ao material da disciplina com a finalidade de tornar o ensino mais contextualizado e atrativo para os estudantes. Essas 
Aula de campo como estratégia complementar no ensino de criptógamas e espermatófitas

estratégias possibilitaram aos estudantes a vivência com estratégias de identificação diversificadas durante a aula de campo.

Conforme aponta Pereira (2013) nessa seção precisa descrever o tipo de delineamento que foi adotado no estudo. "Evitar simplesmente afirmar que se trata de estudo quantitativo ou qualitativo. Em cada uma dessas modalidades há subtipos. É melhor precisar qual deles foi empregado" (PEREIRA, 2013, p. 183). Como exemplo, especifique se é um estudo de revisão de literatura, documental, estudo de cao, estudo exploratório, etc.

Assim, é necessário realizadar a descrição do método adotado, devendo contemplar os passos reaizados para o desenvolvimento do estudo. Apresenta-se de maneira detalhada, participantes ou amostra, os instrumentos, procedimentos, recursos e ferramentas usados, os criterios utilizados na seleção da amostra e a forma como os dados foram coletados, tabulados e analisados.

Todos os tipos de pesquisa devem apresentar material e métodos. Inclusive, poderá ser dividida em subseções: participantes, instrumentos, procedimentos usados para coleta e análise dos dados.

\section{RESULTADOS E DISCUSSÃO}

A atividade de campo foi realizada em dois dias. No primeiro dia, no turno da manhã, logo na chegada ao local da aula (Figura1), foram feitas as devidas instalações do grupo no Campus Experimental de Educação Ambiental e Ecologia da UECE. No turno da tarde foi feita a exploração da primeira trilha ecológica.

Figura 1. Chegada dos estudantes do Curso de Ciências Biológicas da FAEC/UECE ao Campus Experimental de Educação Ambiental e Ecologia da UECE, em Pacoti-Ce.

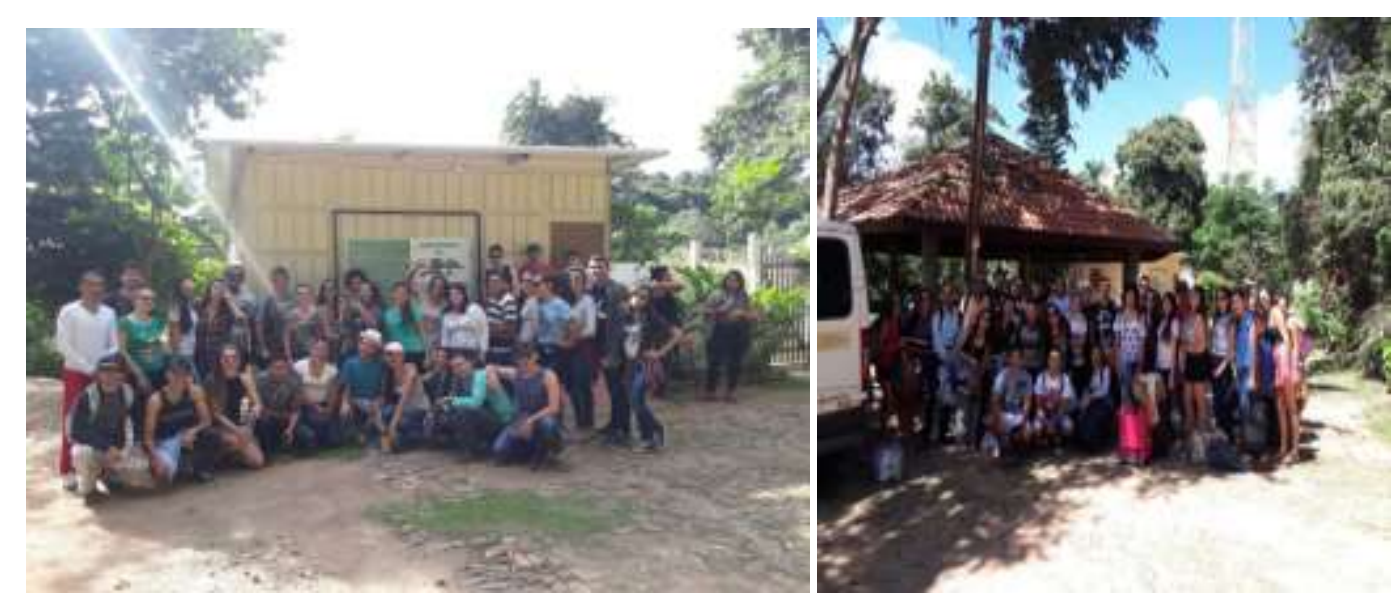


Fonte: Elaborada pelos autores

A exploração da trilha foi acompanhada tanto pelos professores quanto por um guia experiente e conhecedor da região, o qual foi previamente contatado por um dos professores envolvidos na atividade. Benetti (2002) destaca que as aulas de campo são, para os professores, uma oportunidade de inovação de suas práticas docentes, mas ressalta que para um bom aproveitamento desta atividade, é necessário que o docente conheça bem o ambiente a ser explorado neste tipo de aula, no sentido de atender a possíveis questionamentos que sejam gerados durante a atividade em campo.

O local que foi observado é uma região de mata secundária, explorada atualmente apenas para fins acadêmicos e/ou turísticos. Viana et al. (2017) ressaltam que o potencial de utilização de áreas verdes no ensino de Biologia ocorre porque se trata de uma alternativa didática de extrema importância e que pode contemplar diversas áreas do conhecimento, proporcionando uma abordagem interdisciplinar, que pode melhorar a percepção e a compreensão dos estudantes sobre diferentes eixos da natureza.

Nas primeiras observações de espécies vegetais estudadas na disciplina de "Espermatófitas", percebeu-se que os estudantes conseguiam identificar muitas características botânicas exploradas como exemplos nos tópicos estudados na disciplina, tais como: os curiosos tipos de flores e inflorescências (Figura 2), as quais foram todas identificadas com o auxílio do aplicativo “P1@nt Net”, uma ferramenta gratuita e muito útil na identificação de espécies vegetais por meio de imagens, e posterior uso de chaves de identificação. Alguns autores, como Ventura e Freire (2017), explicam que as disciplinas em que prática e teoria são ministradas de maneira indissociável, levam o aluno a colocar em ação os conhecimentos, os conceitos e as novas descobertas em prática, proporcionando um aprendizado mais completo e significativo.

Figura 2. Flores e inflorescências de algumas espécies coletadas pelos estudantes para a produção de exsicatas: 1. Albizia julibrissin 2. Alpinia purpurata 3. Iris germânica 4. Hibiscus schizopetalus 5. Tagetes erecta 6. Anemone nemorosa L. 


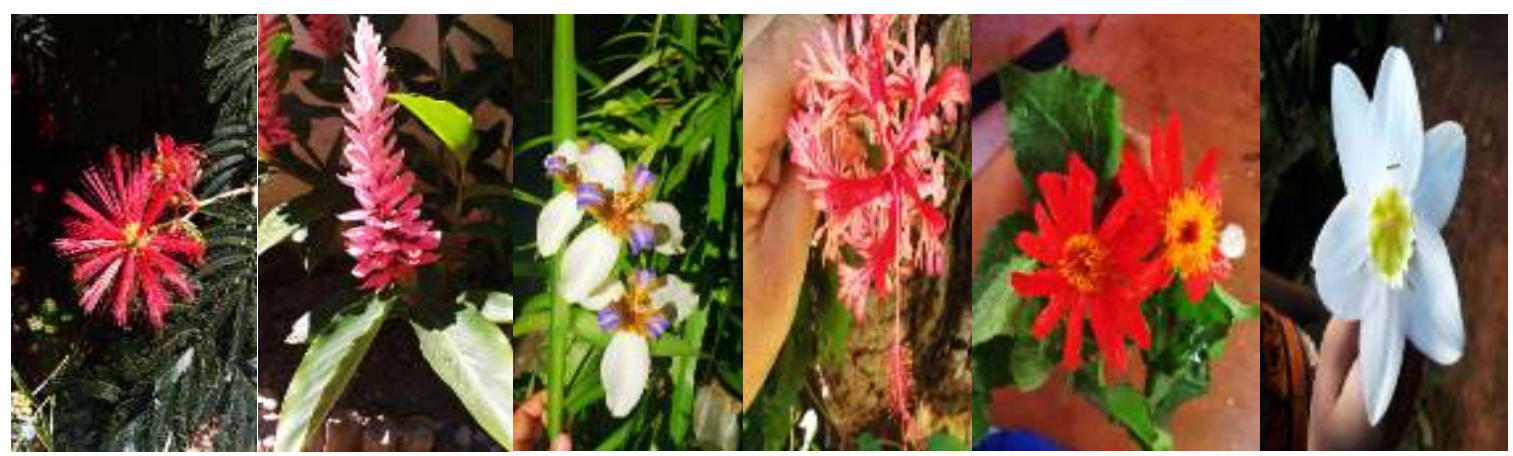

Fonte: Elaborado pelos autores.

A utilização do aplicativo foi muito útil durante a aula de campo, tanto para o reconhecimento de espécies desconhecidas como também para o conhecimento de algumas peculiaridades da espécie fotografada, como: local de ocorrência, estrutura das raízes, caules, folhas, flores e frutos, o que contribuiu para o entendimento e exemplificação durante o estudo do conteúdo de morfologia externa abordado na disciplina de "Espermatófitas". O uso de aplicativos em aulas de campo vem sendo empregado, segundo Barros (2017), como uma figura assídua em meio à realidade pedagógica da rede pública, seja na educação básica ou nas universidades. Outros autores, como Lara e Quartiero (2011), ressaltam que o desenvolvimento das TICs traz uma gama de possibilidades para a inovação da prática pedagógica dos professores, além de tornar o ensino mais atual e dinâmico para os estudantes.

Além da identificação das espécies por meio desta ferramenta, tivemos a oportunidade de colaborar com os dados armazenados no aplicativo. Isso ocorreu quando tentamos identificar uma espécie que nos chamou muita atenção pela aparência de sua inflorescência, a Zingiber spectabile (Figura 3), e vimos que esta não estava descrita na plataforma de dados do “P1@nt Net”.

Figura 3. Zingiber spectabile fotografada em Pacoti-Ce.

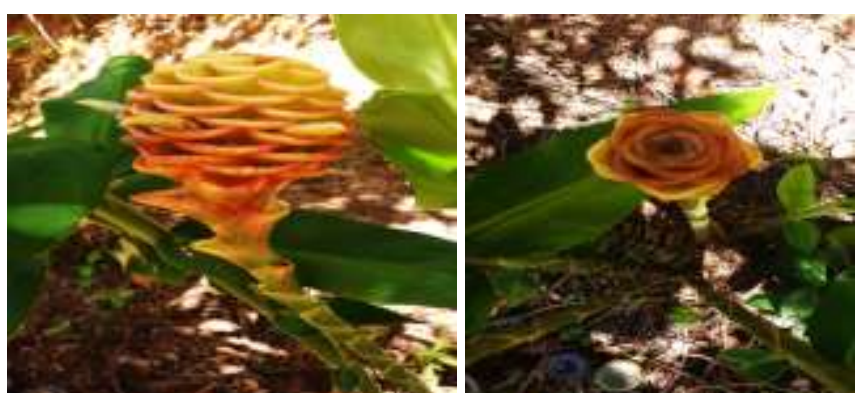

Educação, Psicologia e Interfaces, Volume 2, Número 3, p. 21-37, Setembro/Dezembro, 2018. 
Fonte: Elaborada pelos autores.

Uma amostra da Zingiber spectabile foi coletada, conservada em álcool $70 \%$ e levada para a FAEC/UECE, quando iniciamos a pesquisa sobre a procedência de tal espécie. Desta forma, conseguimos fazer a identificação da espécie e o cadastro na plataforma de dados do aplicativo, o qual dispõe de uma opção que permite que seus usuários cadastrem espécies que ainda não constam na base de dados.

Com relação à disciplina de "Criptógamas" pudemos observar a diversidade de fungos presentes na região, a exemplo de fungos dos filos Basidiomycota e Ascomycota (Figura 4) estudados na disciplina. Percebemos a curiosidade dos estudantes, já que este tipo de organismo não é tão comum na cidade de Crateús-Ce por ser próprio de ambientes mais úmidos. Para Silva (2018), as aulas de campo com trilhas ecológicas em ambientes diferentes da realidade dos estudantes representam um recurso ressignificante na prática pedagógica, uma vez que eleva os níveis experienciais dos indivíduos, que passam a ter interpretações práticas da variedade dos aspectos e dos elementos que compõem a teoria vista em sala de aula.

Figura 4. Fungos dos filos Basidiomycota e Ascomycota

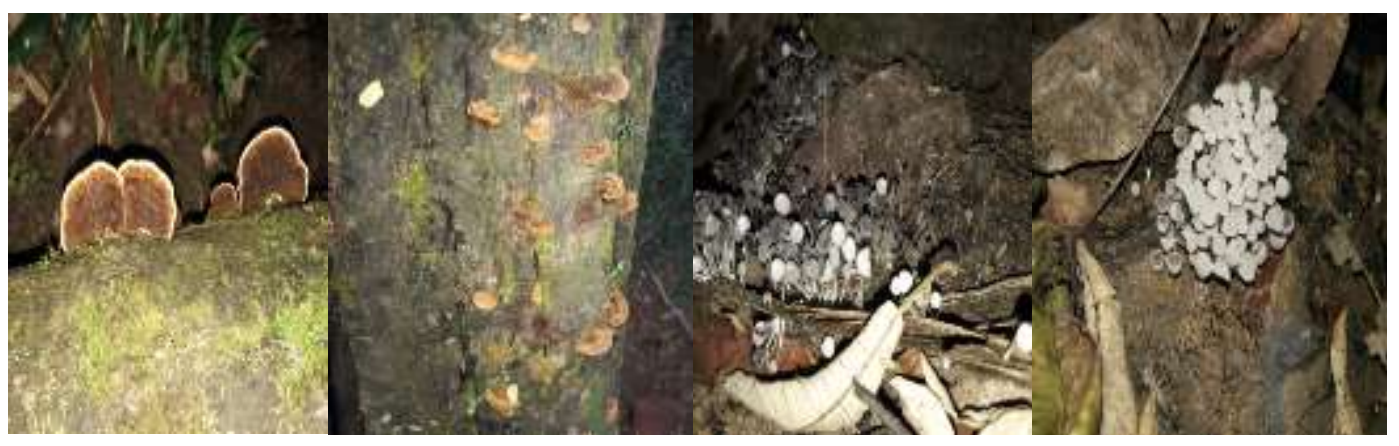

Fonte: Elaborada pelos autores.

Ao longo de toda a aula de campo o professor chamou atenção para algumas relações ecológicas existentes entre os seres vivos, fazendo uma associação direta entre os conhecimentos de botânica e ecologia. As duas observações que mais chamaram a atenção dos estudantes foi a relação de epifitismo entre uma bromélia crescendo sobre o tronco de uma árvore e a relação de simbiose mutualística entre fungos e algas (líquen) observada nos troncos de várias árvores. Isso despertou a atenção dos licenciandos pelo 
Aula de campo como estratégia complementar no ensino de criptógamas e espermatófitas

fato desta relação estar exemplificada em vários livros, mas poucos estudantes tinham observado no ambiente natural (Figura 5).

Figura 5. Relação de epifitismo entre uma bromélia e o tronco de uma planta superior, e relação simbiótica mutualística entre algas e fungos (Líquens).
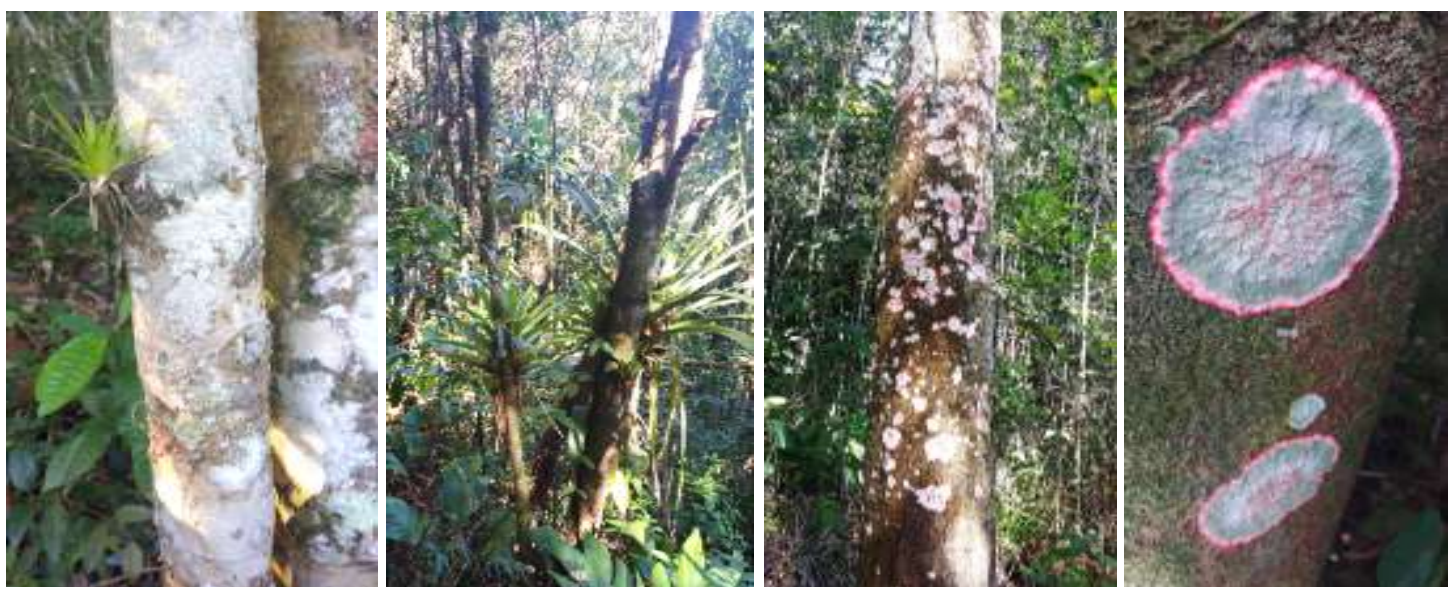

Fonte: Elaborada pelos autores.

Durante o percurso o professor fez algumas observações com destaques específicos relacionados ao conteúdo explorado nas aulas teóricas de "Espermatófitas", tais como: a técnica de anelamento, empregada para cessar o crescimento de algumas plantas, sobretudo de espécies exóticas invasoras, enfatizando sempre que a exclusão do floema funcional presente na porção interna da casca inviabiliza o transporte de fotoassimilados da parte aérea da planta para os órgãos inferiores. O professor destacou também a presença de caules do tipo colmo e raízes adventícias, além de ter dado ênfase ao conteúdo de morfologia externa de folhas, destancando aspectos, como: filotaxia, nomencaltura botânica, diferenças entres folhas simples, compostas e recompostas, já estudados anteriormente (Figura 6).

Figura 6. Explicação do professor sobre os tipos de folhas, técnica de anelamento, caules do tipo colmo e raízes adventícias.
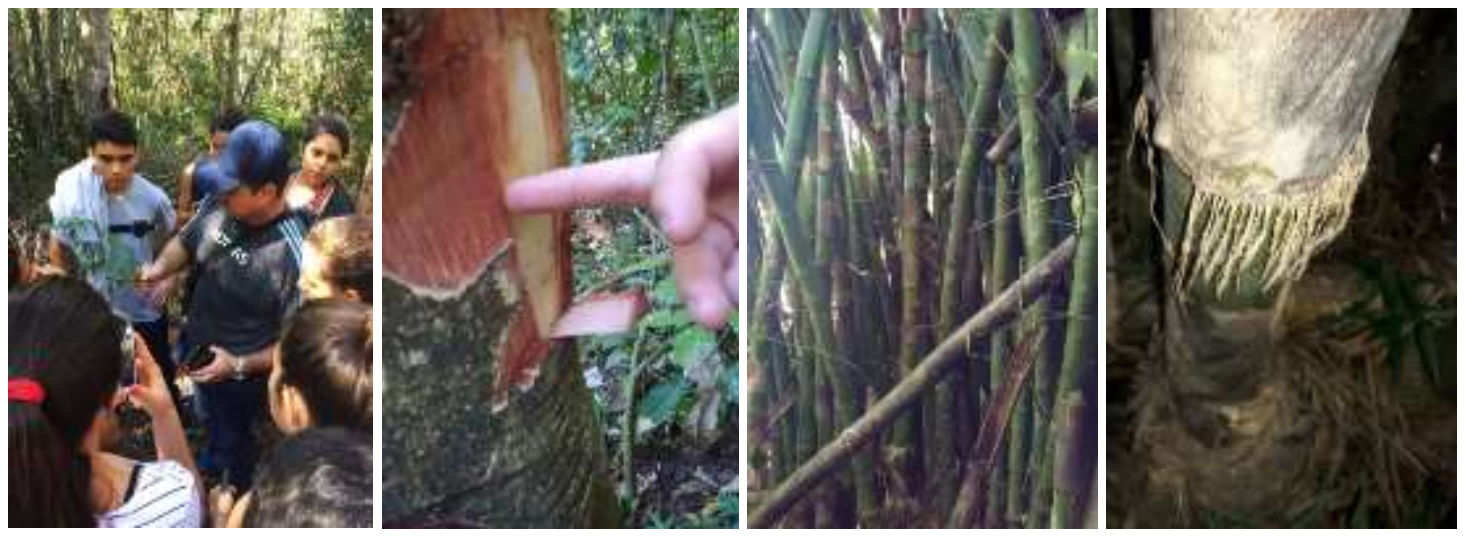

ISSN: 2594-5343. DOI: https://doi.org/10.37444/issn-2594-5343.v2i3.107 
Fonte: Elaborada pelos autores.

Durante as trilhas, os estudantes da disciplina de "Criptógamas", já instruídos durante as aulas teóricas quanto ao conteúdo de Briófitas, fizeram inúmeras observações dessas plantas durante a trilha, além de registros fotográficos. Na ocasião, o professor enfatizou características das Briófitas relacionadas ao habitat, às estruturas vegetativas e reprodutivas, e destacou as gerações gametofítica e esperofítica facilmente observadas em espécies de musgos durante a aula de campo (Figura 7).

Figura 7. Observação de Briófitas.
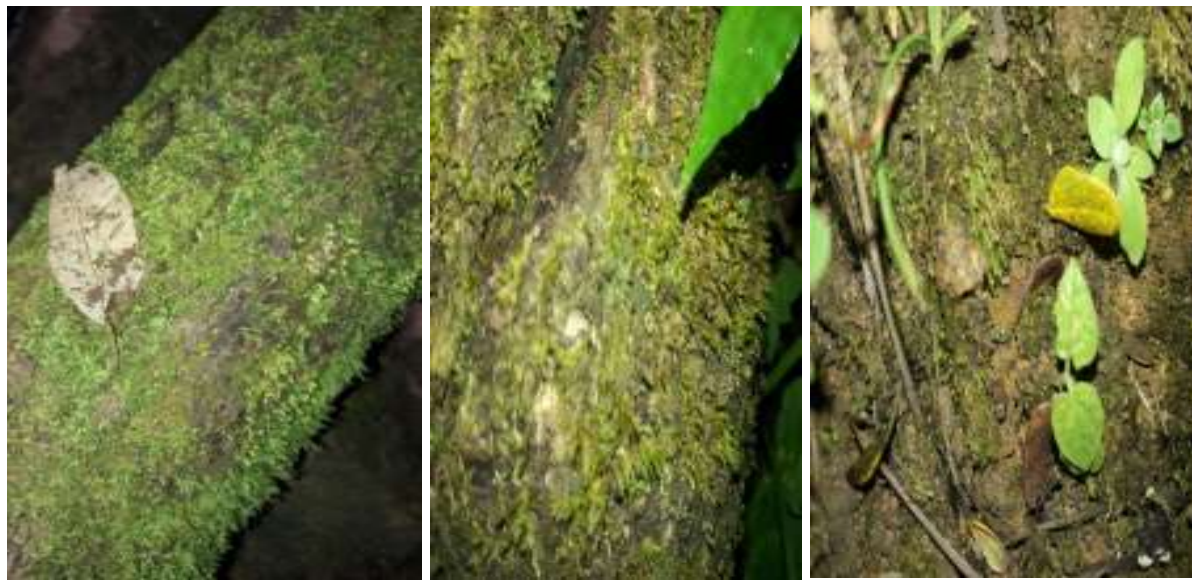

Fonte: Elaborada pelos autores.

David e Oliveira (2018) pontuam que a inserção de aulas de campo no ensino superior dos cursos de Licenciatura em Ciências Biológicas ampliam a discussão e a reflexão na superação da visão dicotômica criada ao longo do tempo entre teoria e prática, possibilitando não apenas a ascensão de novos saberes, mas sobretudo a construção científico-pedagógica da identididade desses futuros docentes.

Durante o percurso realizado nos dois dias da aula de campo, os estudantes fizeram as coletas das espécies que lhes chamaram a atenção e que posteriormente foram colocadas nas prensas de madeira, com o auxílio do professor e da monitora da disciplina, que instruíram o procedimento básico para a preparação de exsicatas, borrifando as amostras vegetais com álcool para conservá-las por maior tempo. Após isso, foram usadas 
Aula de campo como estratégia complementar no ensino de criptógamas e espermatófitas

várias camadas de papelão e papel madeira, de modo a retirar a umidade presente nas amostras.

No âmbito das metodologias empregadas, Braz e Lemos (2014) acreditam que a coleta e a produção de exsicatas são procedimentos de ensino que fomentam uma atitude reflexiva nos estudantes de licenciatura, à medida em que inclui os mesmos como participantes ativos na vivência de experiências práticas que superam a fragmentação dos conteúdos de Botânica.

Após colocar o material nas prensas e ao término de nossa aula em campo, retornamos a Crateús, onde esperamos o período de um mês para que o material das prensas perdesse toda a umidade para que, posteriormente, pudéssemos finalizar a confecção das exsicatas. Após essa etapa as exsicatas foram confeccionadas e colocadas em local arejado, no intuito de conservá-las para que pudessem ser observadas por outras turmas durante a apresentação dos conteúdos de morfologia externa das espermatófitas (Figura 8).

Figura 8. Etapa de confecção das exsicatas.
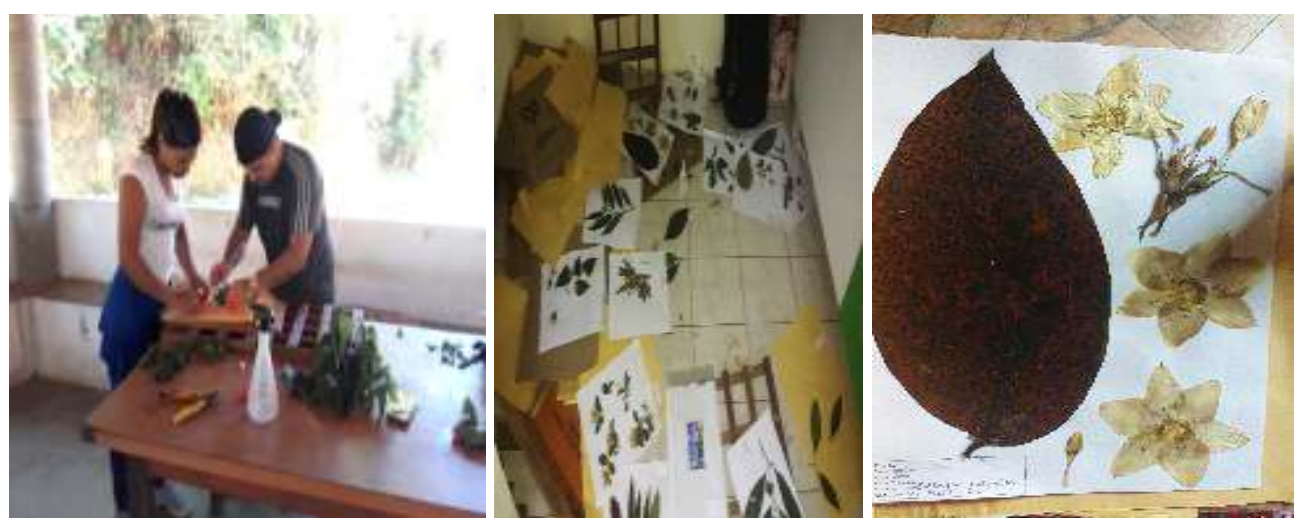

Fonte: Elaborada pelos autores.

\section{CONSIDERAÇÕES FINAIS}

Essa atividade de aula de campo funcionou como uma excelente estratégia na motivação dos discentes para a aprendizagem dos conteúdos ministrados nas disciplinas de "Espermatófitas" e "Criptógamas", permitindo um aprendizado mais eficiente, dinâmico e atrativo, e funcionando como um mecanismo de superação da ótica de que essas disciplinas são abstratas e de difícil compreensão. 
Outra importante contribuição foi o uso da diversificação metodológica permitida por esta atividade, por meio do aplicativo "Pl@nt Net", que além de possibilitar a identificação das espécies vegetais coletadas, nos possibilitou uma importante contribuição por meio do cadastro da espécie Zingiber spectabile para o banco de dados do aplicativo, de modo a contribuir nas pesquisas e nos estudos acadêmicos dos demais usuários da ferramenta.

A metodologia de estudo por meio da observação e coleta permitiu aos estudantes o aprendizado teórico por meio da exploração da vegetação local, o que oportunizou aos discentes a vivência prática dos conceitos em ambas as disciplinas.

A estratégia didática relatada nesse trabalho proporcionou também o aprendizado metodológico sobre os meios de coleta de material botânico, conservação e produção de material acadêmico para a disciplina de "Espermatófitas" (as exsicatas), além dos registros fotográficos selecionados para as duas disciplinas, que poderão ser usados em posteriores atividades de estágio, de monitoria, ou até mesmo em suas futuras atuações docentes.

Esse tipo de atividade mostra aos estudantes de licenciatura a importância da diversificação metodológica, até mesmo no nível superior, incentivando-os a reproduzilas na educação básica e, assim, formar professores cada vez mais atualizados e que se preocupam em inovar as suas práticas docentes por meio da utilização de atividades deste cunho pedagógico. Esse tipo de atividade formativa deixa claro para os licenciandos que por muitas vezes o professor não faz uso de uma determinada prática pelo fato de não conhecê-la, ou seja, por não ter vivenciado durante a sua trajetória acadêmica. Deste modo, quando esse tipo de metodologia faz parte da formação básica do professor, consequentemente refletirá em sua prática profissional no futuro.

A participação da monitora nesta atividade ampliou os seus conhecimentos, tanto no aspecto de conteúdo das disciplinas quanto na vivência e constatação das potencialidades das estratégias metodológicas de ensino que podem ser empregadas, o que proporcionou à estudante uma visão reflexiva acerca da importância na superação de adversidades relacionadas à infraestrutura de ensino e às condições financeiras.

Esse tipo de trabalho reitera a visão de que o ensino sempre pode ser melhorado, em qualquer que seja a realidade, despertando a visão crítica e reflexiva do estudante de 
Aula de campo como estratégia complementar no ensino de criptógamas e espermatófitas

licenciatura sobre o papel do professor, além de enfatizar a importância de metodologias complementares para a aprendizagem no ensino de biologia.

Tal prática motivou a interdisciplinaridade por meio dos conhecimentos advindos das demais disciplinas que fizeram parte dessa aula, mas, sobretudo, da possibilidade de relacionar os saberes de "Espermatófitas" e "Criptógamas", crucial para o estabelecimento de algumas interligações teóricas entre as duas disciplinas, levando à percepção também de que os estudantes conseguiram estabelecer uma conversa entre diversas áreas do conhecimento biológico e, deste modo, resgatar conhecimentos de disciplinas que cursaram anteriormente.

Com o desenvolvimento desta aula de campo pudemos notar a importância do desenvolvimento de ações em grupo, como no caso dos professores, que se uniram para a realização desta aula, o que evidencia o forte potencial de ações colaborativas, mesmo em contextos com recursos financeiros escassos, mas que para estes professores funcionou como um desafio que enriqueceu suas práticas docentes, além do valoroso ganho intelectual e social adquiridos por todos os envolvidos nesta atividade.

\section{REFERÊNCIAS BIBLIOGRÁFICAS}

AGUIAR, G. M, et al. Análise da utilização de estratégias didáticas no ensino de Ciências em escolas de municípios de Pernambuco. Revista Ciência em Extensão, v. 13, n. 2, 2017.

ARNHOLD, A. L.; SQUALLI, M. L. Reflexão Sobre a Importância da Monitoria no Processo Ensino-Aprendizagem em Botânica no Curso de Ciências Biológicas. XXII Seminário de Iniciação Científica. UNIJUÍ-RS. Salão do Conhecimento. 2014.

ARRAIS, M. G. M; SOUSA, G. M; MASRUA, M. L. A. O ensino de botânica: investigando dificuldades na prática docente. Revista da SBEnBio, v. 12, n. 7, 2014.

BARROS, M. A. M. Aprendizagem móvel no ensino de ciências: o que pensam Nossos alunos sobre essa nova modalidade de formação?. Enseñanza de las ciencias, v.5, n. Extra, 2017.

BENETTI, B. A temática ambiental e os procedimentos didáticos: perspectivas de professores de Ciências. In: VIII Encontro Perspectivas do Ensino de Biologia, 2002.

BOGDAN, R; BIKLEN, S. Investigação qualitativa em educação: uma introdução à teoria e aos métodos. Porto: Porto Editora. 1994. 
BRAZ, N.C.S.; LEMOS, J.R. Herbário escolar" como instrumento didático na aprendizagem sobre plantas em uma escola de Ensino Médio da cidade de Parnaíba. Revista Didática Sistêmica, v.16, n. 4, 2014.

DAVID, E. S; OLIVEIRA, I. L. S. A relação teoria e prática esboçada na estrutura curricular do Curso de Licenciatura em Ciências Biológicas da Universidade Federal do Amapá. Estação Científica (UNIFAP), v. 8, n. 1, 2018.

DIAS, M. P. K, et al. Aprendendo ciências e desenvolvendo colaboratividade na Floresta Nacional de Pacotuba (ES) por meio de aulas de campo. InterSciencePlace, v. 12, n. 2, 2017.

GONÇALVES, G. S.; DIAS, H. C.; TERRA, R. P. A aula-campo como recurso para a educação ambiental: uma análise dos ecossistemas costeiros do sul do Espírito Santos ao litoral do município de São Francisco de Itabapoana, RJ. Boletim do Observatório Ambiental Alberto Ribeiro Lamego, v. 4 n. 1, 2010.

KRASILCHIK, M. Prática de Ensino de Biologia. São Paulo: EDUSP, $4^{\mathrm{a}}$ edição, 2008.

LARA, R.; QUARTIEIRO, E. M. Impressões digitais e capital tecnológico: o lugar das TIC na formação inicial de professores. Anais do V Simpósio Nacional da ABCiber, v. 4, n.1, 2011.

MATOS, L. B, et al. Relato de experiências de atividades didáticas como alternativa para dinamizar o ensino de botânica. Educere-Revista da Educação da UNIPAR, v. 16, n. 1, 2016.

NUNES, M. J. M, et al. Herbário didático como ferramenta diferenciada para a aprendizagem em uma escola de ensino médio em Parnaíba, Piauí. Momento-Diálogos em Educação, v. 24, n. 2, 2015.

SILVA, D. C. O papel da aula de campo na formação de professores de biologia da universidade federal de mato grosso, (Dissertação de mestrado), 2018.

SILVA, L. M, et al. Biologia na aula de campo: reconhecendo a interdisciplinaridade através da visita ao geopark araripe. Revista Sapiência: Sociedade, saberes e práticas educacionais, v. 3, n. 3, 2014.

VENTURA, G; FREIRE, L. As finalidades da educação em ciências no currículo mínimo de ciências/biologia: uma análise discursiva da rede estadual do Rio de Janeiro. Alexandria: Revista de Educação em Ciência e Tecnologia, v. 10, n. 1, 2017. 
Aula de campo como estratégia complementar no ensino de criptógamas e espermatófitas

VIANA, I.V, et al. Utilização de áreas verdes como recurso didático para o ensino de ciências. V encontro regional sul do ensino de biologia (EREBIO-SUL) v. 5, n. 2, 2017.

VIVEIRO, A. A; DINIZ, R. E. S. Atividades de campo no ensino das ciências e na educação ambiental: refletindo sobre as potencialidades desta estratégia na prática escolar. Ciência em tela, v. 2, n. 1, 2009.

\section{Credenciais da/os autora/es}

PAIVA, Aparecida Barbosa de. Graduada em Biologia pela Universidade Estadual do Ceará-UECE. Professora substituta na UECE. E-mail: aparecida.barbosa@aluno.uece.br SUDÉRIO, Fabricio Bonfim. Professor Adjunto na UECE, Campus de Crateús, CE, Brasil. E-mail: fabricio.suderio@uece.br

Endereço para correspondência: UECE, Campus de Crateús, CE, Brasil. E-mail: aparecida.barbosa@aluno.uece.br

\section{Como citar este artigo (Formato ABNT):}

PAIVA, Aparecida Baborsa de; SUDÉRIO, Fabrício Bonfim. Aula de campo como estratégia complementar no ensino de criptógamas e espermatófitas. Educação, Psicologia e Interfaces, v.2, n.3, p. 21-37, 2018. DOI: https://doi.org/10.37444/issn2594-5343.v2i3.107

Recebido: 04/02/2018.

Aceito: 26/05/2018. 